\title{
Influence of oxytetracycline susceptibility as a first-line antibiotic on the clinical outcome in dairy cattle with acute Escherichia coli mastitis
}

\author{
Yasunori SHINOZUKA ${ }^{1)}$, Kazuhiro KAWAI ${ }^{1) *}$, Akira TAKEDA ${ }^{2)}$, \\ Michiaki YAMADA ${ }^{1)}$, Fumi KAYASAKI ${ }^{2)}$, Nao KONDO'2), Yoshiko SASAKI ${ }^{2}$, \\ Nahoko KANAI ${ }^{2)}$, Takuma MUKAI'), Masaki SAWAGUCHI'), Masaya HIGUCHI ${ }^{2)}$, \\ Haruka KONDO2), Kouki SUGIMOTO²), Shinogu KUMAGAI'), (sao MURAYAMA ${ }^{3)}$, \\ Yasushi SAKAI ${ }^{3)}$, Kumiko BABA ${ }^{3)}$, Kazuki MAEMICHI ${ }^{3)}$, Takeshi OHISHI ${ }^{3)}$, \\ Toshio MIZUNUMA ${ }^{3)}$, Akiko KAWANA ${ }^{3)}$, Akane YASUDA ${ }^{1)}$ and Aiko WATANABE ${ }^{1)}$
1)School of Veterinary Medicine, Azabu University, 1-17-71 Fuchinobe, Sagamihara, Kanagawa 252-5201, Japan 2) NOSAI Doto, 11-6-1 Nishi-6jou-minami, Nakashibetsu, Shibetsu, Hokkaido 086-1106, Japan \\ ${ }^{3)}$ NOSAI Miyagi, 1-8-10 Uesugi, Aoba, Sendai, Miyagi 980-0011, Japan
}

J. Vet. Med. Sci.

81(6): 863-868, 2019

doi: 10.1292/jvms.19-0035

Received: 16 January 2019 Accepted: 31 March 2019 Published online in J-STAGE: 10 April 2019
ABSTRACT. The purpose of this study was to clarify the therapeutic effects of oxytetracycline (OTC) as a first-line antibiotic in cattle with acute Escherichia coli mastitis and systemic signs. Drug susceptibility was determined by the minimum inhibitory concentration (MIC) of E. coli isolated from cows with acute $E$. coli mastitis $(\mathrm{n}=38)$. Cattle were divided into OTC-susceptible $(S, \mathrm{n}=30)$ and OTC-resistant $(\mathrm{R}, \mathrm{n}=8)$ groups. They were further subdivided according to susceptibility to the antibiotic used as a second treatment, into susceptible-susceptible (SS, n=30), resistantsusceptible $(R S, n=5)$, and resistant-resistant $(R R, n=3)$ groups. Clinical signs on the day after initial treatment were compared between $\mathrm{S}$ and $\mathrm{R}$ groups as short-term indicators of treatment effects. The 28-day survival rate of cattle was then compared among SS, RS, and RR groups as a long-term indicator of treatment effects. There were no differences in clinical signs between $\mathrm{S}$ and $\mathrm{R}$ groups on the day after the first dose, but the 28-day survival rate was significantly greater in the SS group than in the RR group $(P=0.04)$. The results demonstrated that an effective drug is essential for first-line treatment of acute coliform mastitis. However, anticipating the effectiveness of a first-line antibiotic based on clinical symptoms at the second day of treatment is impossible. It is important to build a picture of drug resistance trends in cattle herds for empirical selection of antibiotics to be administered.

KEY WORDS: acute E. coli mastitis, minimum inhibitory concentration (MIC), outcome, oxytetracycline

Mastitis in dairy cattle leads to reduced milk yield and quality, and thus causes enormous financial harm to dairy farmers [4]. Mastitis is mainly caused by bacterial infections, but various different pathogens have been reported [19]. Mastitis from gramnegative bacilli is largely caused by Escherichia coli or Klebsiella spp., and the seriousness of clinical disease ranges widely: from mild cases with only an abnormality in milk, to moderate cases showing localized symptoms, to severe cases showing systemic symptoms [14]. With mastitis due to coliform bacteria, it has been reported that if symptoms are not systemic (i.e. in mild or moderate cases), treatment with antibiotics is not required [11]. Nonetheless, a third of mastitis cases due to coliform bacteria are severe (acute coliform mastitis, ACM), and they can at times be fatal. Even if the cow recovers, a marked decrease in milk yield following the disease can still cause significant economic damage [5]. This is a significant problem, and appropriate treatment is needed.

In cases of coliform mastitis with severe symptoms, there is a risk that the level of bacteria in milk may increase to uncontrollable levels, leading to the development of bacteremia; in such cases, antibiotics are used to reduce bacteria numbers. Research to date on antibiotic treatment of ACM has included considerable numbers of experimental and field studies, and Suojala et al. concluded that the optimal antibiotic treatment for ACM due to E. coli is a fluoroquinolone administered at the 
maximum dose, with treatment by third- or fourth-generation cephalosporin antibiotics also recommended [18]. These are among the most useful classes of antibiotics in both human and veterinary medical applications [1], and from a public health perspective, caution is needed in the way they are used to ensure that they maintain their effectiveness. In Japan, based on a risk assessment by the Food Safety Commission, the Ministry of Agriculture, Forestry and Fisheries has limited the use of fluoroquinolone and thirdor fourth-generation cephalosporin antibiotics to second-line drugs as a risk management measure. This restriction applies equally to ACM.

Oxytetracycline (OTC) is a bacteriostatic antibiotic with a broad spectrum of activity, and it has been approved in Japan as a drug for treatment of livestock diseases. It is often used as a first-line drug in the treatment of ACM [9] due to the low release of lipopolysaccharides accompanying the elimination of E. coli [2]. Selection of a drug that is effective at eradicating the pathogen is essential in the treatment of infectious disease, and the resistance rate of bovine E. coli to OTC in Japan was reported to be $29.1 \%$ in 2008 and $20.0 \%$ in 2009 [10]. It is therefore likely that ACM caused by OTC-resistant E. coli occurs and is treated, but to date there have been no reports clinically evaluating first-dose effects of OTC on ACM that take drug susceptibility into account.

The purpose of the present study was therefore to clarify effects of susceptibility to the first dose of OTC on treatment results in naturally occurring ACM cases.

\section{MATERIALS AND METHODS}

The study was approved by the ethical committee at Azabu University.

\section{Animals and experimental design}

We collected 57 clinical ACM cases among cattle in Hokkaido and Miyagi Prefecture that developed the condition between August 2016 and December 2017. From those cases, 38 lactating cows given a first-line antibiotic treatment of systemic OTC $(10 \mathrm{mg} / \mathrm{kg}$ body weight) and with a pretreatment sample culture yielding E. coli alone were enrolled in the present study. All 38 cattle presented with systemic symptoms, and the severity of the disease was classified from moderate to severe on the basis of a prior report [22]. None of the cattle had a history of vaccination with the J-5 strain of E. coli. Following diagnosis by a local veterinarian, each cow underwent a clinical evaluation, and milk samples were collected aseptically prior to antibiotic administration. To ensure animal welfare, all cattle were given further treatments as deemed necessary by the attending veterinarian. To evaluate the effect of first-line antibiotic treatment, the cattle were first divided into OTC-susceptible $(\mathrm{S})(\mathrm{n}=30)$ and OTC-resistant $(\mathrm{R})(\mathrm{n}=8)$ groups on the basis of minimum inhibitory concentration (MIC) of OTC for isolated $E$. coli strains. Next, S and R groups were further subdivided into susceptible-susceptible (SS) (n=30), resistant-susceptible (RS) ( $\mathrm{n}=5)$, and resistant-resistant $(\mathrm{RR})(\mathrm{n}=3)$ groups on the basis of a combination with susceptibility and resistance to the antibiotic administered on the second day after onset of mastitis.

\section{Microbiology tests and MIC measurement}

Milk samples were stored under refrigeration until culture. Pathogens in the milk were identified according to the National Mastitis Council (NMC) procedure [7]. The broth dilution method was used to determine MICs according to guidelines from the Committee for Clinical and Laboratory Standards Institute (CLSI) [20]. Antibiotic susceptibility and resistance were determined on the basis of the MIC breakpoints established by the Japanese Veterinary Antimicrobial Resistance Monitoring System [10].

\section{Assessment of treatment outcome}

Local udder and systemic clinical signs were observed immediately before treatment (on day 0 ) and on the following three days after initiation of treatment (days 1,2, and 3), as short-term indicators of the effects of treatment. All clinical observations were carried out by veterinarians, and observation criteria were standardized to exclude bias as a result of multiple examining veterinarians. Localized udder signs observed as present or absent were: swollen udder, udder firmness, and abnormal milk. Systemic signs observed were: decreased appetite, diarrhea, low skin temperature, ocular hyperemia, dehydration, and astasia. Since the antibiotic residue period in meat affects a farmer's decision to cull, the endpoint of group survival rate at 28 days from onset was taken as a long-term index of the effects of treatment. Survival in each group was confirmed by data from the Japanese cattle traceability system of the National Livestock Breeding Center.

\section{Statistics}

Fisher's exact test was used to compare clinical data between S and R groups for each observed clinical symptom from day 0 to day 3. The 28-day survival rate was compared among SS, RS, and RR groups using the log-rank test, and adjustment was subsequently carried out using the Holm method. A log-rank trend test was also used to analyze trends in each group. In addition, multivariate analysis was conducted using a Cox proportional hazard regression model; for this, the explanatory variables (factors considered likely to affect prognosis) were age, days in milk, parity, and general clinical score at the initial examination, and the objective variable was the 28-day group survival rate. All statistical analyzes were performed using EZR (ver. 1.27; Saitama Medical Center, Jichi Medical University, Saitama, Japan), a graphical user interface for R (The R foundation for Statistical Computing, Vienna, Austria) [8]. 
Table 1. Minimum inhibitory concentration (MIC) distribution for Escherichia coli $(\mathrm{n}=38)$ from acute coliform mastitis in dairy cows

\begin{tabular}{|c|c|c|c|c|c|c|c|c|c|c|c|c|c|c|}
\hline \multirow{2}{*}{ Antibiotic } & \multirow{2}{*}{$\mathrm{n}$} & \multicolumn{13}{|c|}{$\operatorname{MIC}(\mu \mathrm{g} / \mathrm{m} l)$} \\
\hline & & $<0.125$ & 0.25 & 0.5 & 1 & 2 & 4 & 8 & 16 & 32 & 64 & 128 & 256 & $>256$ \\
\hline Oxytetracycline & 38 & & & & 5 & 23 & 2 & & & & & & 5 & 3 \\
\hline Enrofloxacina) & 28 & 28 & & & & & & & & & & & & \\
\hline Kanamycin $^{\text {a) }}$ & 1 & & & & & & 1 & & & & & & & \\
\hline
\end{tabular}

The breakpoint used is defined according to the National Veterinary Assay Laboratory (NVAL 2013). The resistance breakpoint is indicated by the red line. a) Administerd as a second-line antibiotics.

\section{RESULTS}

Results of microbial tests and division into groups by antibiotic susceptibility of $E$. coli isolated from the mastitic udder milk, and distribution of the MIC of OTC for all strains, showed bimodality (Table 1). Thirty strains showed susceptibility (susceptible group, S), and eight strains showed resistance (resistant group, R) to OTC used as initial treatment on day 0, with a resistance rate of $20.5 \%$. Antibiotics administered on day 1 were enrofloxacin (ERFX, $n=28)$, OTC ( $n=8)$, kanamycin $(K M, n=1)$, or none ( $n=1)$. Antibiotics administered to the $\mathrm{S}$ group $(\mathrm{n}=30)$ on day 1 (ERFX, $n=24$; OTC, $n=6)$ were both effective (SS group). In the R group $(\mathrm{n}=8)$, an effective drug (ERFX, $\mathrm{n}=4 ; \mathrm{KM}, \mathrm{n}=1$ ) was administered to five cattle (RS group); of the remaining three cattle (RR group), two were administered a drug to which organisms were resistant (OTC), and one died before further treatment.

\section{Clinical score}

There were no significant differences in clinical scores for observed local signs between the groups from day 0 to day 3 . For systemic signs, there was no significant difference between clinical scores in groups on either day 0 or day 1 , but both groups showed improvement on day 1 following treatment (Table 2). On day 2, the R group showed a significantly greater proportion of ocular hyperemia than the $\mathrm{S}$ group $(P=0.0497)$. On day 3 , the R group showed a significantly greater proportion of not only ocular hyperemia $(P=0.0164)$, but also decreased appetite $(P=0.0301)$ and astasia $(P=0.0404)$.

\section{Twenty eight-day survival rate}

The 28-day survival rate by group was $80.0 \%$ (24/30 cattle) in the SS group, $60.0 \%$ (3/5 cattle) in the RS group, and $33.3 \%$ ( $1 / 3$ cattle) in the RR group (Fig. 1). The 28 -day survival rate was significantly higher in the SS group than in the RR group $(P=0.04)$. There was also a trend for the 28 -day survival rate to decrease in the group order: $\mathrm{SS}$, RS, and RR $(P=0.015)$. In the Cox proportional hazard regression model corrected for age, days in milk, parity, and general clinical score at initial examination, the 28-day survival rate was significantly greater in the SS group than in the RR group $(P=0.001805)$ (Table 3 ).

\section{DISCUSSION}

In the present study on cases of naturally-occurring ACM, MIC values for OTC with respect to E. coli isolated showed a bimodal distribution, and on the basis of microbiological breakpoint, the resistant proportion was $20.5 \%$. This result resembles a report on resistance monitoring of $E$. coli derived from healthy or diseased cattle [10]. This therefore demonstrates that $E$. coli with resistance to OTC is present in an environment in which ACM can occur.

The clinical condition of all cases improved on day 1 as a result of initial systemic administration of OTC, regardless of whether the bacterial strain was susceptible. Acute ACM symptoms appear as a result of an excessive inflammatory reaction to lipopolysaccharides, a structural component of the cell wall of gram-negative bacilli [15], and it has been shown that the severity of symptoms depends on the amount of lipopolysaccharides in the udder [6]. In addition, it has been reported that experimental injection of unmixed lipopolysaccharides into the udder can reproduce the same pathological conditions as ACM [23]. It is therefore likely that in the acute phase of ACM the clinical response following the first administration of an effective antibiotic for pathogen control is relatively small. At the same time, when compared to the susceptible group, the resistant group showed an increasingly greater proportion of individuals exhibiting signs such as decreased appetite and ocular hyperemia from day 2 to day 3 , and the proportion of astasia also increased. It has been reported that bacteremia occurs in 32\% of cases of severe ACM [21], and the worsening clinical condition was probably the effect of incomplete bacterial control by the first-line treatment. In order to elucidate this, additional tests taking into account the bacterial load of blood or milk are necessary.

As a long-term evaluation, cattle were further grouped into combinations according to susceptibility to the antibiotic administered on day 1, and the 28-day survival rate was evaluated. The SS group showed a significantly higher 28-day survival rate than the RR group. In addition, the 28-day survival rate showed a decreasing trend in the order: SS, RS, and RR. This trend was presumably due to the increased proportion of cattle that showed worsening of septicemia-like systemic signs in the R group from day 2 onward, such as ocular hyperemia, decreased appetite, and astasia, which led to death or culling. Further, the RS and SS groups were both administered effective drugs at the second examination, and while the difference was not significant, the RS group showed a lower 28-day survival rate. These results show that in ACM treatment, if an effective antibiotic is not used by day 1 at the latest, the 28-day survival rate decreases. 
Table 2. Comparison of systemic and local signs between the $\mathrm{S}$ group and the $\mathrm{R}$ group up to 3 days after onset

\begin{tabular}{|c|c|c|c|c|}
\hline Parameter & Days after onset & Susceptible group $(\mathrm{n}=30)$ & Resistant group $(\mathrm{n}=8)$ & $P$-value ${ }^{\text {a) }}$ \\
\hline \multicolumn{5}{|l|}{ Local udder clinical signs } \\
\hline \multirow[t]{4}{*}{ Swelling } & 0 & 30 & 8 & NT \\
\hline & 1 & 24 & 7 & 0.57 \\
\hline & 2 & 18 & 6 & 0.39 \\
\hline & 3 & 16 & 5 & 0.68 \\
\hline \multirow[t]{4}{*}{ Firmness } & 0 & 26 & 8 & 0.56 \\
\hline & 1 & 21 & 7 & 0.16 \\
\hline & 2 & 16 & 5 & 0.68 \\
\hline & 3 & 16 & 4 & 1 \\
\hline \multirow[t]{4}{*}{ Milk abnormality } & 0 & 30 & 8 & NT \\
\hline & 1 & 29 & 7 & NT \\
\hline & 2 & 26 & 7 & 1 \\
\hline & 3 & 25 & 7 & 0.57 \\
\hline \multicolumn{5}{|l|}{ Systemic clinical signs } \\
\hline \multirow[t]{4}{*}{ Decreased appetite } & 0 & 30 & 8 & NT \\
\hline & 1 & 16 & 5 & 0.67 \\
\hline & 2 & 9 & 2 & 1 \\
\hline & 3 & 4 & 4 & 0.030 \\
\hline \multirow[t]{4}{*}{ Diarrhea } & 0 & 11 & 2 & 0.69 \\
\hline & 1 & 4 & 2 & 0.32 \\
\hline & 2 & 1 & 1 & 0.36 \\
\hline & 3 & 3 & 1 & 1 \\
\hline \multirow[t]{4}{*}{ Low skin temperature } & 0 & 21 & 7 & 0.65 \\
\hline & 1 & 14 & 4 & 0.69 \\
\hline & 2 & 3 & 4 & 0.016 \\
\hline & 3 & 1 & 2 & 0.090 \\
\hline \multirow[t]{4}{*}{ Ocular hyperemia } & 0 & 10 & 4 & 0.43 \\
\hline & 1 & 10 & 4 & 0.39 \\
\hline & 2 & 5 & 4 & 0.050 \\
\hline & 3 & 3 & 4 & 0.016 \\
\hline \multirow[t]{4}{*}{ Dehydration } & 0 & 11 & 4 & 0.69 \\
\hline & 1 & 11 & 1 & 0.39 \\
\hline & 2 & 2 & 1 & 0.49 \\
\hline & 3 & 3 & 1 & 1 \\
\hline \multirow[t]{4}{*}{ Astasia } & 0 & 7 & 2 & 1 \\
\hline & 1 & 5 & 2 & 0.60 \\
\hline & 2 & 4 & 1 & 1 \\
\hline & 3 & 2 & 3 & 0.040 \\
\hline
\end{tabular}

a) Fisher's exact test. All parameters were not recorded for all cows. NT, note tested.

Table 3. Final Cox proportional hazards regression model for the analysis of effect of acute E.coli mastitis treatment on risk for a 28 days survival rate at the cow level between 1st and 2nd line antibiotic susceptibility

\begin{tabular}{|c|c|c|c|c|}
\hline \multirow{2}{*}{ Variable $^{\text {a) }}$} & \multirow{2}{*}{ Hazard ratio } & \multicolumn{2}{|c|}{$95 \%$ cnfidence interval } & \multirow{2}{*}{$P$-value } \\
\hline & & Lower & Upper & \\
\hline SS & Referent & & & \\
\hline $\mathrm{RS}$ & 3.33 & 0.60 & 18.39 & 0.17 \\
\hline RR & 54.95 & 4.44 & 680.50 & $<0.01$ \\
\hline
\end{tabular}

a) Combination with susceptibility and resistance to the antibiotics used on the first and second day (SS: susceptible-susceptible, RS: resistant-susceptible, RR: resistant-resistant).

Interestingly, in the SS group, where effective antibiotics were administered from the first-line treatment onwards, a few individuals were culled from 14 days after onset. The main reason for cattle being culled after they passed the ACM acute phase and were showing systemic recovery was an economic judgment based on reduced productivity due to lowered milk yield [17]. 
The reason reported is that it is difficult to produce and maintain therapeutic concentrations in milk via systemic administration of OTC [16]; therefore, it appears there may have been incomplete pathogen control within the udder. However, all of the cases culled within 28 days in the present study had concomitant administration of effective antibiotics within the udder, so the relationship with localized pathogen control within the udder is unclear.

At the same time, damage to mammary tissue caused by reactive oxygen species [12] or proteases [13] derived from neutrophils has been reported to be a primary factor in decrease of milk yield and quality after the onset of ACM [3]. ACM treatment given to increase the 28-day survival rate must bring about not only recovery of systemic symptoms, but also recuperation of milk yield, and as such pathogen control by means of an effective antibiotic alone may be insufficient.

The selection of an agent to which the pathogen is susceptible is essential in the treatment of infectious disease. The present study shows the importance of using an effective antibiotic in the treatment of ACM at least until the second day of disease, and it also clarifies that the susceptibility or resistance to OTC of the pathogen cannot be conjectured from the clinical response on the second day. It generally takes $48 \mathrm{hr}$ to obtain the results of drug susceptibility tests, which means that reflecting results of drug susceptibility tests in the treatment of cattle tested is not a realistic prospect in the case of ACM. Thus, empiric antibiotic selection is extremely important in treatment carried out within the first $48 \mathrm{hr}$ of diagnosis (at the time of initial and secondary examinations), and the selection criteria must be based on scientific evidence. Even though it may not be possible to make use of results from drug susceptibility tests in the treatment of cattle tested, obtaining a picture of drug resistance trends in the herd will allow judgment criteria to be fortified before empiric antibiotic selection for treatment of ACM in that herd. Actively performing drug susceptibility tests is thus considered to be important. Nonetheless, acute phase ACM pathogenesis does not only depend on the pathogen, but is also intimately related to the bacterial load and the amount of lipopolysaccharides present [6]. There is, therefore, a need for comprehensive research that includes not only antibiotic susceptibility testing, but also assessment of bacterial load and lipopolysaccharides to appropriately evaluate antibiotic treatment of ACM.

The present study showed that if OTC is used in the initial treatment of ACM caused by OTC-resistant E. coli, the prognosis worsens. If an antibiotic for initial treatment of ACM is to be selected empirically, it is essential to select an antibiotic that may be expected to have sufficient effectiveness on the basis of drug resistance trends (antibiogram) within the herd.

\section{REFERENCES}

1. Collignon, P., Powers, J. H., Chiller, T. M., Aidara-Kane, A. and Aarestrup, F. M. 2009. World Health Organization ranking of antimicrobials according to their importance in human medicine: a critical step for developing risk management strategies to control antimicrobial resistance from food animal production. Clin. Infect. Dis. 49: 132-141. [Medline] [CrossRef]

2. Evans, M. E. and Pollack, M. 1993. Effect of antibiotic class and concentration on the release of lipopolysaccharide from Escherichia coli. J. Infect. Dis. 167: 1336-1343. [Medline] [CrossRef]

3. Gröhn, Y. T., Wilson, D. J., González, R. N., Hertl, J. A., Schulte, H., Bennett, G. and Schukken, Y. H. 2004. Effect of pathogen-specific clinical mastitis on milk yield in dairy cows. J. Dairy Sci. 87: 3358-3374. [Medline] [CrossRef]

4. Halasa, T., Huijps, K., Østerås, O. and Hogeveen, H. 2007. Economic effects of bovine mastitis and mastitis management: a review. Vet. Q. 29: 18-31. [Medline] [CrossRef]

5. Hertl, J. A., Schukken, Y. H., Welcome, F. L., Tauer, L. W. and Gröhn, Y. T. 2014. Pathogen-specific effects on milk yield in repeated clinical mastitis episodes in Holstein dairy cows. J. Dairy Sci. 97: 1465-1480. [Medline] [CrossRef]

6. Hoeben, D., Burvenich, C., Trevisi, E., Bertoni, G., Hamann, J., Bruckmaier, R. M. and Blum, J. W. 2000. Role of endotoxin and TNF- $\alpha$ in the pathogenesis of experimentally induced coliform mastitis in periparturient cows. J. Dairy Res. 67: 503-514. [Medline] [CrossRef]

7. Hogan, J. S., Gonzalez, R. N., Harmon, R. J., Nickerson, S. C., Oliver, S. P., Pankey, J. W. and Smith, K. L. 1999. Laboratory Handbook on Bovine Mastitis (Revised ed.), National Mastitis Council Inc., Madison.

8. Kanda, Y. 2013. Investigation of the freely available easy-to-use software 'EZR' for medical statistics. Bone Marrow Transplant. 48: $452-458$. [Medline] [CrossRef]

9. Kiku, Y. 2015. Recent occurrence and control strategy of bovine mastitis. The Journal of Farm Animal Infectious Disease 4: 109-132 (in Japanese).

10. Koike, R., Ozawa, M., Kawanishi, M. and Uchiyama, M. 2013. A Report on the Japanese Veterinary Antimicrobial Resistance Monitoring System -2008 to 2011-. National Veterinary Assay Laboratory, Tokyo.

11. Lago, A., Godden, S. M., Bey, R., Ruegg, P. L. and Leslie, K. 2011. The selective treatment of clinical mastitis based on on-farm culture results: II. Effects on lactation performance, including clinical mastitis recurrence, somatic cell count, milk production, and cow survival. J. Dairy Sci. 94: 4457-4467. [Medline] [CrossRef]

12. Lauzon, K., Zhao, X., Bouetard, A., Delbecchi, L., Paquette, B. and Lacasse, P. 2005. Antioxidants to prevent bovine neutrophil-induced mammary 
epithelial cell damage. J. Dairy Sci. 88: 4295-4303. [Medline] [CrossRef]

13. Mehrzad, J., Desrosiers, C., Lauzon, K., Robitaille, G., Zhao, X. and Lacasse, P. 2005. Proteases involved in mammary tissue damage during endotoxin-induced mastitis in dairy cows. J. Dairy Sci. 88: 211-222. [Medline] [CrossRef]

14. Pinzón-Sánchez, C. and Ruegg, P. L. 2011. Risk factors associated with short-term post-treatment outcomes of clinical mastitis. J. Dairy Sci. 94: 3397-3410. [Medline] [CrossRef]

15. Piotrowska-Tomala, K. K., Bah, M. M., Jankowska, K., Lukasik, K., Warmowski, P., Galvao, A. M. and Skarzynski, D. J. 2015.

Lipopolysaccharides, cytokines, and nitric oxide affect secretion of prostaglandins and leukotrienes by bovine mammary gland during experimentally induced mastitis in vivo and in vitro. Domest. Anim. Endocrinol. 52: 90-99. [Medline] [CrossRef]

16. Pyörälä, S. 2009. Treatment of mastitis during lactation. Ir. Vet. J. 62 Suppl 4: S40-S44. [Medline] [CrossRef]

17. Seegers, H., Fourichon, C. and Beaudeau, F. 2003. Production effects related to mastitis and mastitis economics in dairy cattle herds. Vet. Res. 34: 475-491. [Medline] [CrossRef]

18. Suojala, L., Kaartinen, L. and Pyörälä, S. 2013. Treatment for bovine Escherichia coli mastitis - an evidence-based approach. J. Vet. Pharmacol. Ther. 36: 521-531. [Medline] [CrossRef]

19. Watts, J. L. 1988. Etiological agents of bovine mastitis. Vet. Microbiol. 16: 41-66. [Medline] [CrossRef]

20. Watts, J. L., Fajt, V. R., Schwarz, S., Papich, M. G., Fritsche, T. R., Silley, P., Bade, D. J., Heine, H. S., Wu, C. C., Brown, S. D., Hunter, R. P. and Zurenko, G. E. 2013. Performance Standards for Antimicrobial Disk and Dilution Susceptibility Tests for Bacteria Isolated from Animals. 4th edn. Clinical and Laboratory Standards Institute, Wayne.

21. Wenz, J. R., Barrington, G. M., Garry, F. B., McSweeney, K. D., Dinsmore, R. P., Goodell, G. and Callan, R. J. 2001. Bacteremia associated with naturally occuring acute coliform mastitis in dairy cows. J. Am. Vet. Med. Assoc. 219: 976-981. [Medline] [CrossRef]

22. Wenz, J. R., Garry, F. B. and Barrington, G. M. 2006. Comparison of disease severity scoring systems for dairy cattle with acute coliform mastitis. J. Am. Vet. Med. Assoc. 229: 259-262. [Medline] [CrossRef]

23. Werner-Misof, C., Pfaffl, M. W. and Bruckmaier, R. M. 2007. Dose-dependent immune response in milk cells and mammary tissue after intramammary administration of lipopolysaccharide in dairy cows. Vet. Med. (Praha) 52: 231-244. [CrossRef] 